\title{
UTILIZAÇÃO DA CLASSIFICAÇÃO NÃO-SUPERVISIONADA NA INTEGRAÇÃO E INTERPRETAÇÃO DE DADOS GEOF́́SICOS EM CUBA CENTRO-ORIENTAL
}

\author{
Rigoberto Lazaro Prieto Cainzos, ${ }^{1}$ Elisabete Maria Pascholati, ${ }^{2}$ Carlos Roberto de Souza Filho ${ }^{3}$
}

Recebido em 30 out., 2002 / Aceito em 2 dez., 2003

Received 0ct. 30, 2002 / Accepted Dec. 2, 2003

\begin{abstract}
This paper presents results from unsupervised classification of magnetic (airborne), gravimetric and gamma-ray spectrometric (airborne) data in central-eastern Cuba, with the objective of assisting regional geologic and tectonic-structural interpretation in the area. This portion of Cuba comprises broad sectors of key geologic units recognized in the island, including the Cretaceous volcanic arc (VVA), the Mesozoic ophiolites, the margin of the Bahamas continental platform (Upper Jurassic-Upper (retaceous) and the Cenozoic cover. The area's unique geological characteristic makes it an excellent 'laboratory' to use and evaluate potential field data and multivariate statistic methods. The study revealed that geophysical classes vielded through these methods correlate well with several geologic formations and tectonic features found in the area.
\end{abstract}

Keywords: unsupervised classification, geophysical data, Cuba.

\section{RESUMO}

0 presente trabalho tem por objetivo a ưtilização da classificação não-supervisionada de dados geofísicos aéreos (magnéticos e de espectrometria de raios gama) e gravimétricos em Cuba Centro-Oriental, com o intuito de gerar subsídios para interpretação geológica regional e tectono-estrutural na área de estudo. A região centro-oriental de Cuba abrange amplos setores das principais unidades geológicas documentadas no arquipélago, incluindo o Arco Vulcânico Cretácico (AVC), os ofiolitos Mesozóicos, a margem continental da plataforma das Bahamas (Jurássico Superior-Cretáceo Superior) e a cobertura sedimentar Cenozóica. As características geológicas da área a tornam um interessante 'Iaboratóriio' para utilização de dados geofíisicos e para avaliação de métodos estatísticos multivariados. 0 estudo revelou que as classes geofíiscas, derivadas da aplicação desses métodos aos dados, possuem uma boa correlaçãao com as formações geológicas e ambientes tectono-estruturais da área.

Palavras-chave. classificaçã̃o não-supervisionada; dados geofíisicos; Cuba

\footnotetext{
' Laboratório de Ecologia da Paisagem/Centro de Ciências Agrárias - Cx.Postal 6001 - Universidade Estadual de Londrina - CEP: 86051-970 - Londrina - PR - E-mail: rigoberto@uel.br ${ }^{2}$ Instituto de Geociências - Universidade Estadual de Campinas - Cx.Postal 6152 - Campinas - São Paulo - Tel.: (19) 3788 4573/4535 - Fax: (19) 3289-6215 - E-mail: paschol@ige.unicamp.br ${ }^{3}$ Instituto de Geociências - Universidade Estadual de Campinas - Cx.Postal 6152 - Campinas - São Paulo - Tel.: (19) 37884535 - Fax: (19) 3289-6215 - E-mail: beto@ige.unicamp.br
} 


\section{INTRODUÇÃOO}

A análise estatística multivariada de dados magnéticos, de espectrometria de raios gama, gravimétricos e/ou eletromagnéticos, tem sido aplicada em geologia com o objetivo de sintetizar informações, agrupando características geológicas e permitindo a classificação e a relação das mesmas com determinados ambientes geológicos (HARRIS 1989; PIRES; HARTHILL, 1989; PIRES, 1990; DUVAL; VULKAN, 1993; EBERLE, 1993).

Harris (1989), realizou a classificação não-supervisionada de dados aerogamaespectrométricos, empregando a análise de grupamento de médias migratórias (migrating means clusten), numa área da Nova Escócia, Canadá. 0 autor realizou diversas classificações, combinando os canais gamaespectrométricos e razões entre radioelementos, dos quais obteve bons resultados quanto à correlação com a geologia.

Pires e Harthill (1989) e Pires (1990), aplicaram a análise de grupamento ( $G$-mode, K-médias, Q-mode) em áreas do Estado de Goiás, Brasil. Os autores concluíram que ao integrarem dados magnéticos residuais e de espectrometria de raios gama, contagem total (CT), potássio (K), tório (eTh) e urânio (eU), obtinha-se uma boa correlação entre os resultados obtidos e o mapa geológico.

Duval e Vulkan (1993) aplicaram a análise de grupamento (c/uster ana/ysis) em uma área de Nevada. Os parâmetros geofíisicos empregados foram as concentrações de $\mathrm{K}$, eTh, eU, campo magnético residual (T) e gravidade. Baseados no trabalho de Pires (1990), processaram o campo $\mathrm{T}$ com 0 operador de pseudogravidade (BARANOV, 1957), para obter melhor correlaçã̃o com o campo gravimétrico. Os resultados indicaram uma boa correlação entre o mapa obtido da análise de grupamento e a geologia da área.

Eberle (1993) empregou a análise de grupamento e análise discriminante linear (stepwise linear discriminated analysis) numa área ao sul do Lago Vitoria (Tanzania). Os parâmetros geofísicos utilizados foram as concentrações de K, eTh, eU, campo magnético residual e resistividade aparente. Os resultados obtidos foram satisfatórios e contribuíram para aprimorar o mapa geológico da área.

A análise de grupamento calcula, a partir da técnica de máxima verossimilhança, a correlação das amostras partindo da distância mínima (distância euclidiana) entre elas, levando em consideração, como peso, a média e o desvio-padrão das mesmas (DAVIS, 1976).

Considerando a eficácia desta técnica na classificação nãosupervisionada de dados (PARKS, 1966; PIRKLE et al., 1984; CRÓSTA, 1993), na área de estudo, Cuba centro-oriental, este método foi utilizado segundo duas abordagens e visando dois objetivos principais: (i) a análise tectono-estrutural, empregando como amostras de treinamento dados aeromagnéticos (reduzidos ao pólo) e gravimétricos (anomalia Bouguer); (ii) a relação do mapa geológico da área com os dados gamaespectrométricos aéreos (CT, K, eTh, eU) e a segunda e terceira principais componentes ( $\mathrm{PC2}$ e $\mathrm{PC}$ ) derivadas desses dados.

\section{SÍNTESE GEOLÓGICA DA ÁREA DE ESTUDO}

A área de estudo, Cuba centro-oriental, apresenta exposições dos dois principais níveis estruturais mapeados no arquipélago (Figura 1): o substrato dobrado e o neo-autóctone (ITURRALDE-VINENT et al., 2000).

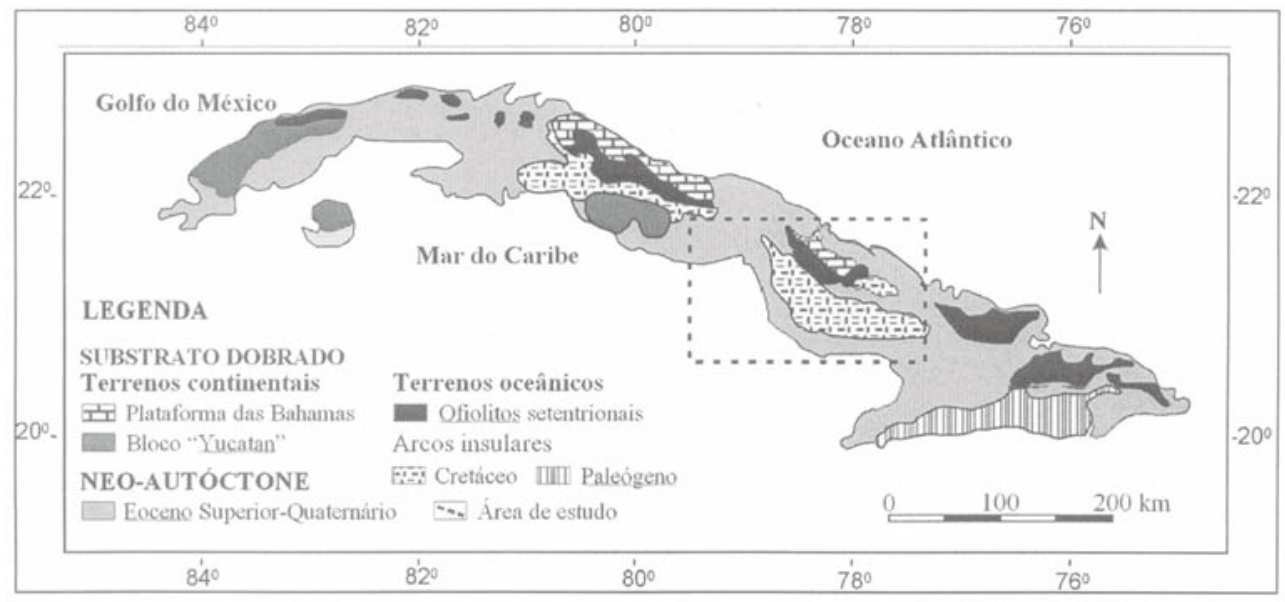

Figura 1 - Mapa geológico generalizado de Cuba: substrato dobrado e neo-autóctone (modificado de ITURRALDE-VINENT et al., 2000). Figure I-Geologic map of Cuba: folded substratum and the neo-autochthonous (modified from ITURRALDE-VINENT et al, 2000). 
0 substrato dobrado é constituído por diversas unidades alóctones, de natureza continental e oceânica, cuja origem e evolução está relacionada a processos orogenéticos ocorridos fora dos limites atuais do território cubano. À unidade de natureza continental pertencem os terrenos da Plataforma das Bahamas (Zona Remédios) e Sequêencias do
Protocaribe. As unidades de natureza oceânica incluem partes da crosta antiga do Caribe (ofiolitos do Cinturão Setentrional) e 0 Arco Vulcânico Cretácico (AVC). 0 neo-autóctone é representado por rochas e estruturas desenvolvidas principalmente na posição atual de Cuba (Figura 2 e Figura 3).

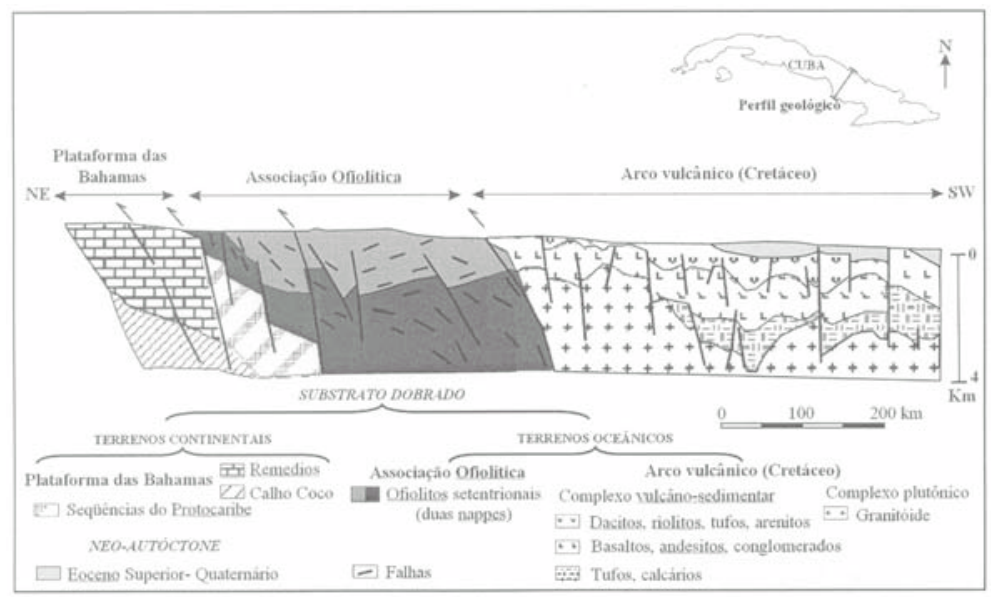

Figura 2 - Perfil geológico esquemático das principais estruturas do substrato dobrado em Cuba centro-oriental (modificado de ITURRALDE-VINENT et al., 2000).

Figure 2 - Schematic geologic section comprising the main structures of the folded substratum and the neo-autochthonous in central-eastern Cuba (modified from ITURRALDE-VINENT et al.,2000).

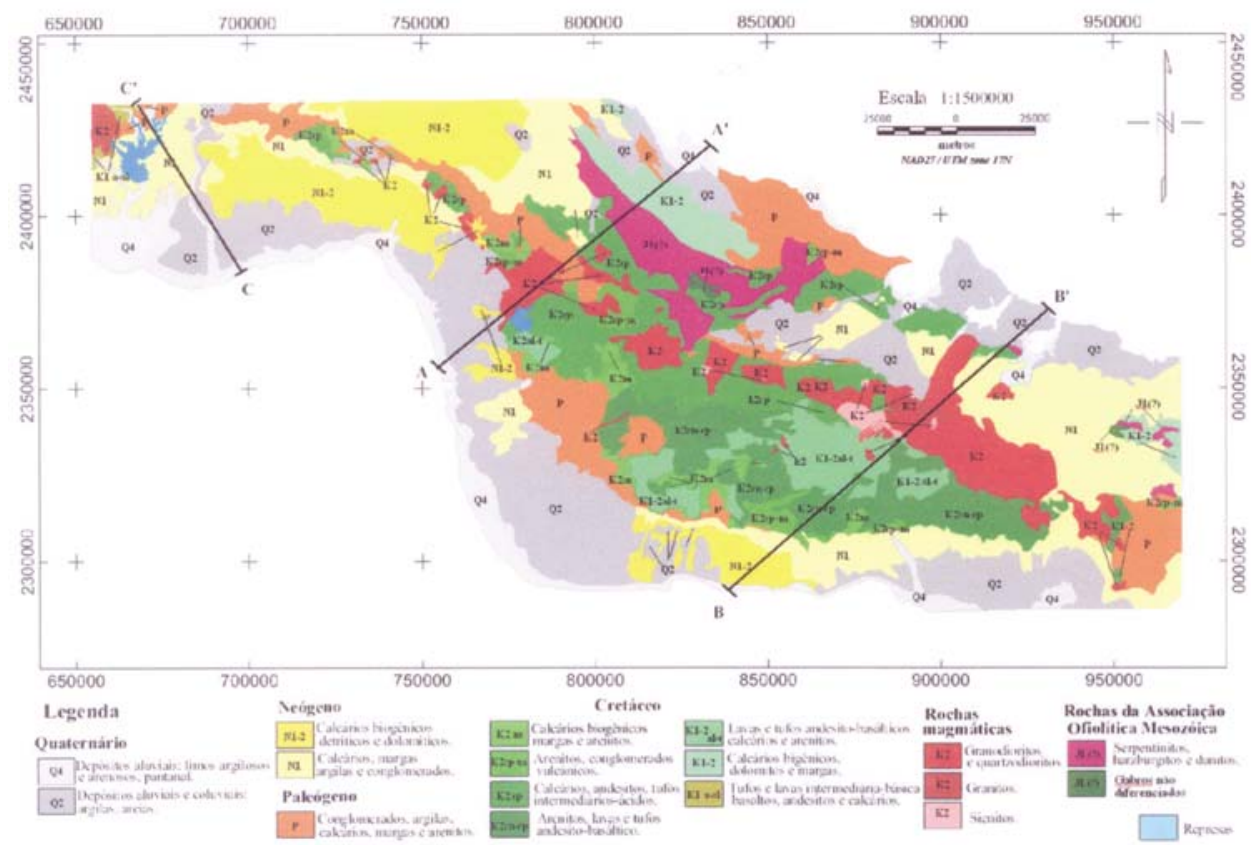

Figura 3 - Mapa geológico de Cuba centro-oriental (modificado de PUSCHAROVSKY, 1988). Figure 3-Geologic map of central-eastern Cuba (modified from PUSCHAROVSKY, 1988). 


\section{DADOS GEOFÍSICOS}

\section{Campo magnético}

0 campo magnético anômalo (reduzido ao pólo) da área de estudo, mostra valores entre -2984 nT e $3258 \mathrm{nT}$ (Figura 4). Ao longo da porção N-NE, observa-se o campo magnético com baixa intensidade e valores intermédios entre -171 nT e $143 \mathrm{nT}$.

A faixa central apresenta um intenso campo de valores positivos, $>143 \mathrm{nT}$, e forte gradiente, cujo eixo central tem azimute de $135^{\circ}$.
Nessa faixa, destacam-se setores de extensão variável, cujas intensidades são maiores que $400 \mathrm{nT}$ (Figura 4).

0 campo magnético de valores negativos apresenta-se com intensidade variável, até $<-2000 \mathrm{nT}$. Na porção norte da área, apresenta-se alongado na direção NW-SE e nas porções oeste e sul, sem forma característica (Figura 4).

\section{Campo gravimétrico}

0 campo gravimétrico (anomalia Bouguer) na área, apresentase com valores entre -56 mGal e $62 \mathrm{mGal}$ (Figura 5).

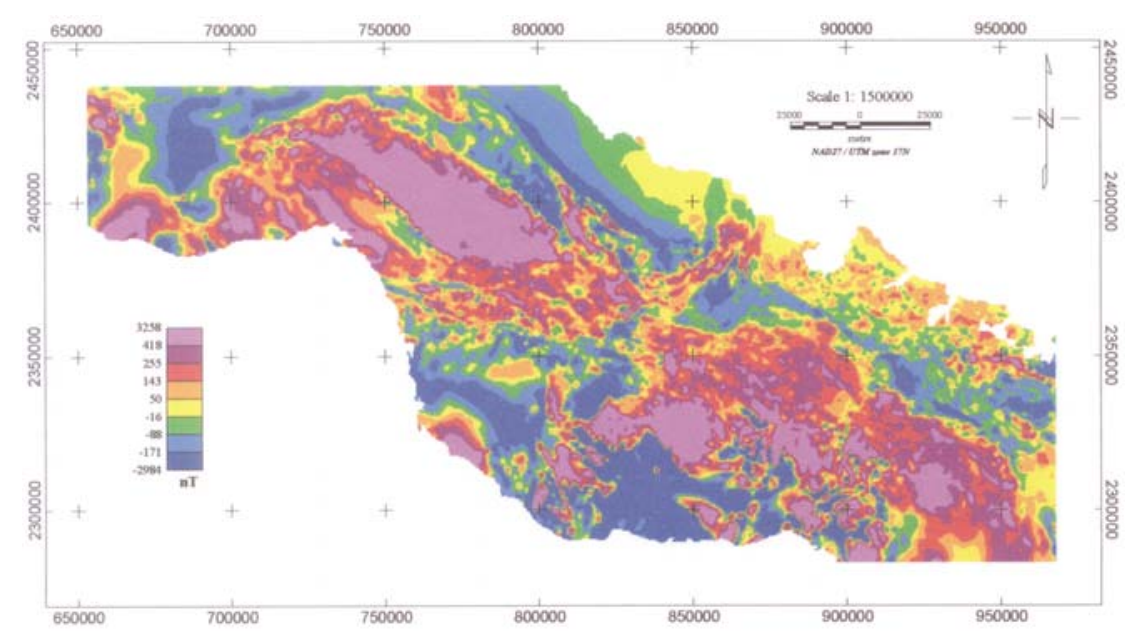

Figura 4 - Mapa de campo magnético reduzido ao pólo, Cuba centro-oriental. Figure 4- Map of magnetic field reduced to the pole, central-eastern Cuba.

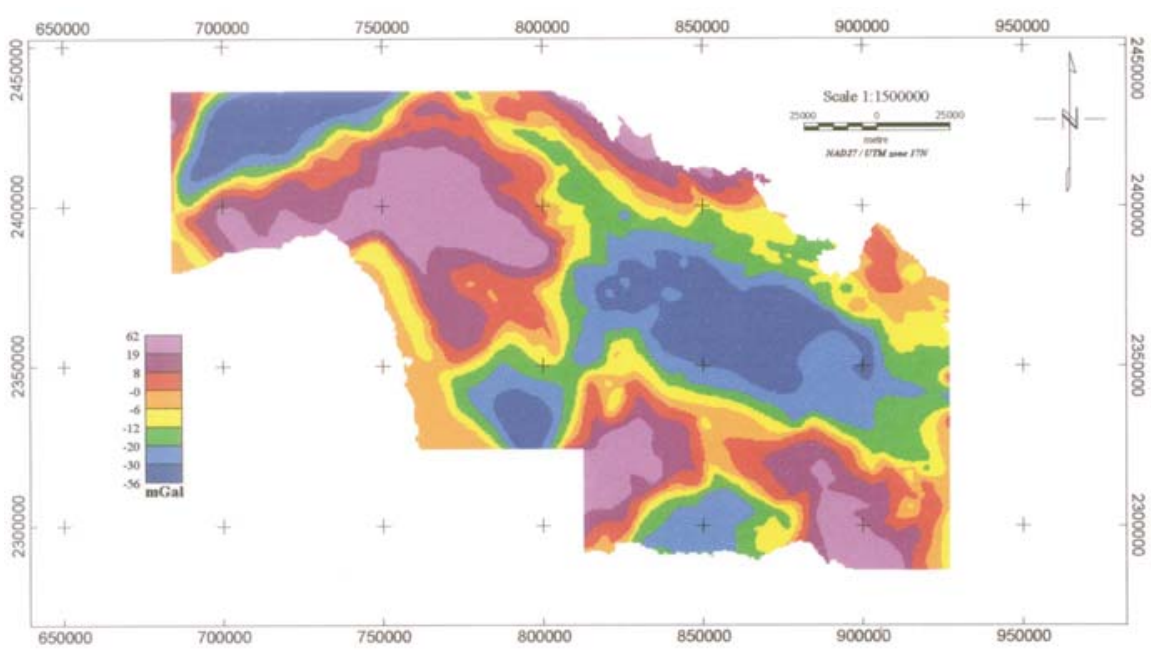

Figura 5 - Mapa gravimétrico (anomalia Bouguer), Cuba centro-oriental. Figure 5- Gravimetric map (Bouguer anomaly), central-eastern Cuba. 
Ao longo da porção N-NE, 0 campo gravimétrico apresenta intensidade gradual, variando de - $12 \mathrm{mGal}$ a $62 \mathrm{mGal}$. Nas porções centro-oeste, SW e SE, observam-se extensos campos de valores positivos, simétricos e com intensidades de até $62 \mathrm{mGal}$ (Figura 5).

0 campo gravimétrico de valores negativos, na porção NW, apresenta grande magnitude, com intensidades $<-20 \mathrm{mGal}$, sendo alongado segundo a direção NE-SW. Características similares são também observadas no centro-leste; entretanto o campo ocorre segundo a direçũo NW-SE. A SW e S, o campo mostra-se menos extenso e simétrico, com intensidades de até - $56 \mathrm{mGal}$ (Figura 5).

\section{ESPECTROMETRIA DE RAIOS GAMA}

0 campo gamaespectrométrico é apresentado através de mapa ternário (RGB), o qual mostra de forma integrada as características dos radioelementos na área. 0 radioelemento potássio foi alocado no espaço correspondente ao vermelho, tório ao verde e urânio ao azul (Figura 6).

Os resultados mostram uma distribuição da concentração de potássio por todo o setor, estando as maiores intensidades situadas principalmente na porção central, numa faixa alongada de direção NWSE. Os radioelementos urânio e tório aparecem, geralmente, coincidentes nas porç̄es norte, oeste e sul do setor.

\section{CLASSIFICAÇÃO NÃO-SUPERVISIONADA DE DADOS AEROMAGNÉTICOS E GRAVIMÉTRICOS}

A aplicação da técnica aos dados aeromagnéticos (reduzidos ao pólo) e gravimétricos (anomalia Bouguer) visando à análise geológicoestrutural, mostrou resultados interessantes. As variáveis foram agrupadas em seis classes (Figura 7).

A classe 1 aparece na porção sul. Esta área é caracterizada por valores magnéticos negativos altos e gravimétricos positivos baixos, na média (Tabela 1). É associada a um bloco abatido, constituindo uma estrutura de bacia relacionada ao AVC, com grandes espessuras de sedimentos, de composição variada.

A classe 2, mais difusa que a anterior (Figura 7), apresenta-se com valores negativos dos campos magnético e gravimétrico (Tabela 1). Devido a sua distribuição no setor, esta classe é associada a diferentes ambientes geotectônicos. A norte, inclui a zona de sutura e blocos abatidos que constituem estruturas de bacias. A oeste e sul compreendem blocos abatidos, às vezes constituindo bacias, relacionados à evoluçãa do Arco Cretácico.

A classe 3 encontra-se localizada ao longo da porção nortenordeste do setor e, de forma disseminada, nas áreas restantes (Figura 7). A porção a norte-nordeste do setor é caracterizada por valores médios

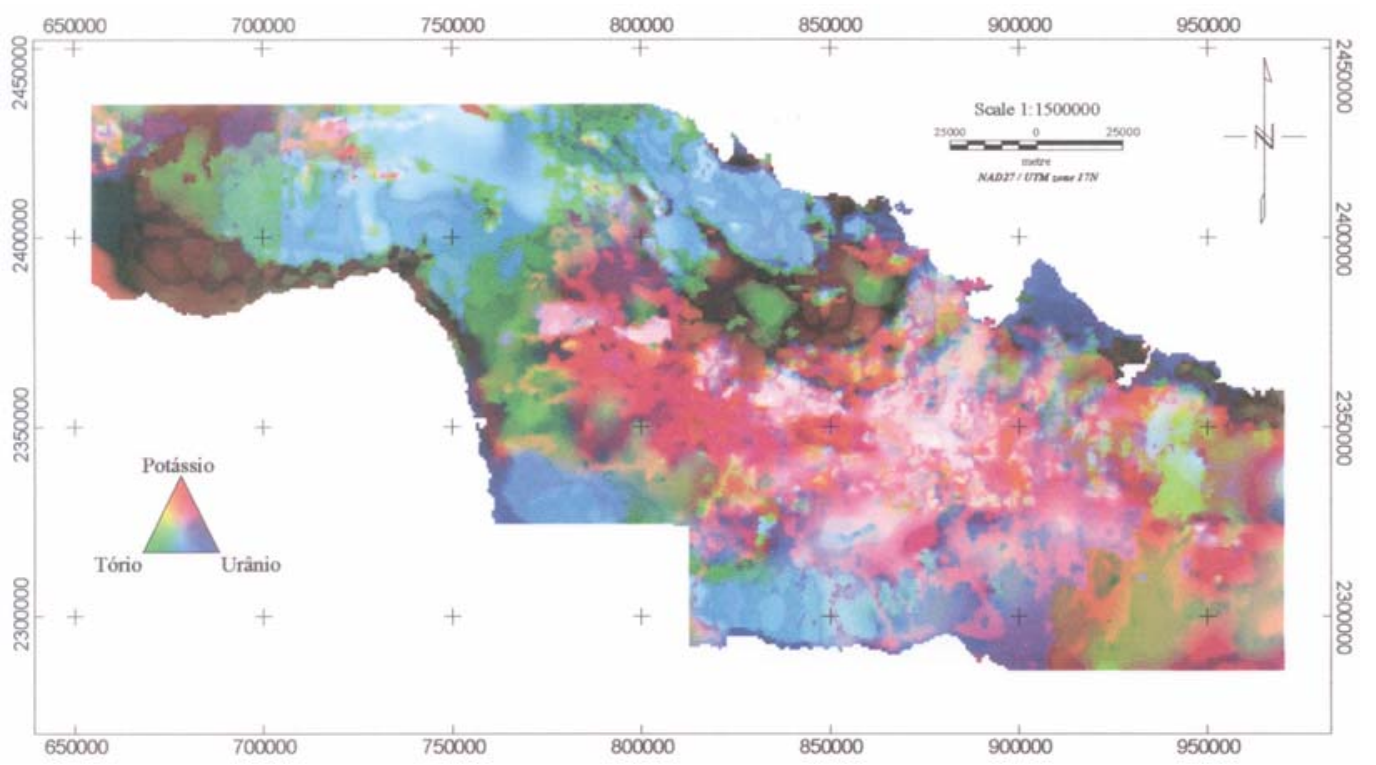

Figura 6 - Mapa Ternário (K-R/eTh-G/eU-B), Cuba centro-oriental.

Figure 6- Ternary map (K-R/eTh-G/eU-B), central-eastern Cuba. 
dos campos magnético e gravimétrico (Tabela 1), e compreende 0 ambiente tectono-estrutural relacionado às rochas continentais pertencentes à margem da Plataforma das Bahamas. Já as áreas restantes estão relacionadas a sedimentos de variada composição do arco vulcânico.
A classe 4, tanto por sua distribuição (Figura 7) quanto pela magnitude dos campos físicos (Tabela 1), compreende seqüências vulcânicas de composição variada, relacionadas à fase vulcanomagmática do Arco Cretácico.

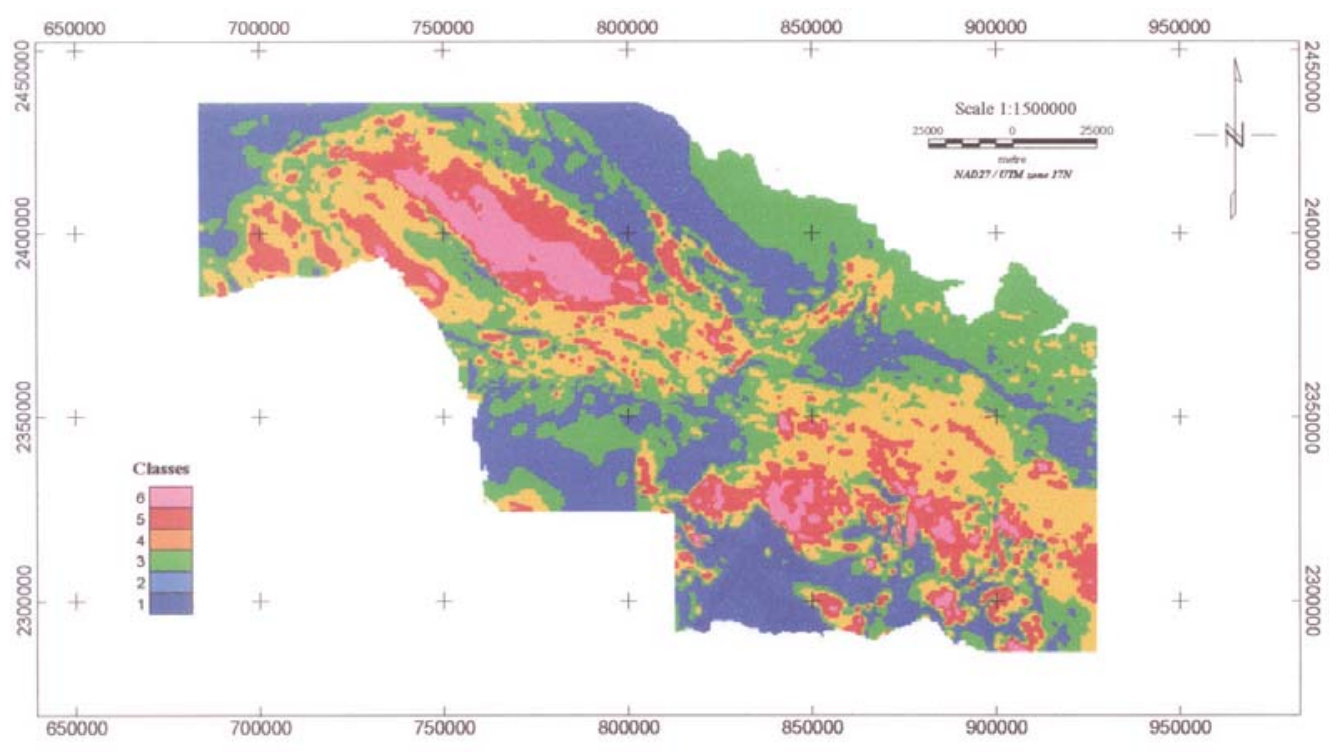

Figura 7 - Mapa de classificação não-supervisionada de dados aeromagnéticos e gravimétricos, Cuba centro-oriental. Figure 7 - Unsupervised classification map of the airborne magnetic and gravimetric data, central-eastern Cuba.

Tabela 1 - Estatística da análise de grupamento (cluster analysis) das variáveis campo magnético (reduzido ao pólo - nT) e campo gravimétrico (anomalia Bouguer - mgal).

Table 1-Cluster analysis statistics of the magnetic field (pole reduction - nT) and gravimetric field (Bouguer anomaly - mgal) data.

\begin{tabular}{|c|c|c|c|c|c|c|}
\hline & \multicolumn{3}{|c|}{$\begin{array}{c}\text { Campo magnético } \\
\text { (reduzido ao pólo) } \\
\mathrm{nT}\end{array}$} & \multicolumn{3}{|c|}{$\begin{array}{c}\text { Campo gravimétrico } \\
\text { (anomalia Bouguer) } \\
\text { mGal }\end{array}$} \\
\hline & $\begin{array}{c}\text { Valor } \\
\text { mínimo }\end{array}$ & $\begin{array}{c}\text { Valor } \\
\text { máximo }\end{array}$ & Média & $\begin{array}{c}\text { Valor } \\
\text { mínimo }\end{array}$ & $\begin{array}{c}\text { Valor } \\
\text { máximo }\end{array}$ & Média \\
\hline Classe 1 & -2983 & -381 & -621 & -40 & 61 & 3 \\
\hline Classe 2 & -382 & -64 & -162 & -56 & 60 & -12 \\
\hline Classe 3 & -65 & 134 & 28 & -54 & 59 & -8 \\
\hline Classe 4 & 134 & 387 & 243 & -54 & 57 & -7 \\
\hline Classe 5 & 383 & 805 & 540 & -49 & 56 & 7 \\
\hline Classe 6 & 804 & 3225 & 1087 & -35 & 54 & 24 \\
\hline
\end{tabular}


0 agrupamento dos valores mais intensos dos campos físicos nas classes 5 e 6 (Tabela 1), indica que tais classes abrangem focos magmáticos em diferentes localidades do AVC.

\section{CLASSIFICAÇÃO NÃO-SUPERVISIONADA DE DADOS AEROGAMAESPECTROMÉTRICOS}

Oito classes foram obtidas com a aplicação da técnica (Figura 8), empregando-se, como amostras de treinamento, as seguintes variáveis: contagem total (CT), concentração dos radioelementos potássio
(K), tório (eTh), urânio (eU) e a segunda (PC2) e terceira (PC3) principais componentes dos dados gamaespectrométricos (estas últimas oferecem melhores resultados ao mapeamento em relação às razões dos radioelementos). Na Tabela 2 são mostrados os valores máximo, mínimo e médio das variáveis (T, K, eTh e eU, para cada classe. Como pode ser observado na Figura 6 e na Tabela 2, as classes 1 e 2 são representadas por teores baixos dos radioelementos, não existindo um predomínio radiogeoquímico nas mesmas. Estas classes representam as formações geológicas recentes, associadas à etapa neo-autóctone do cinturão dobrado.

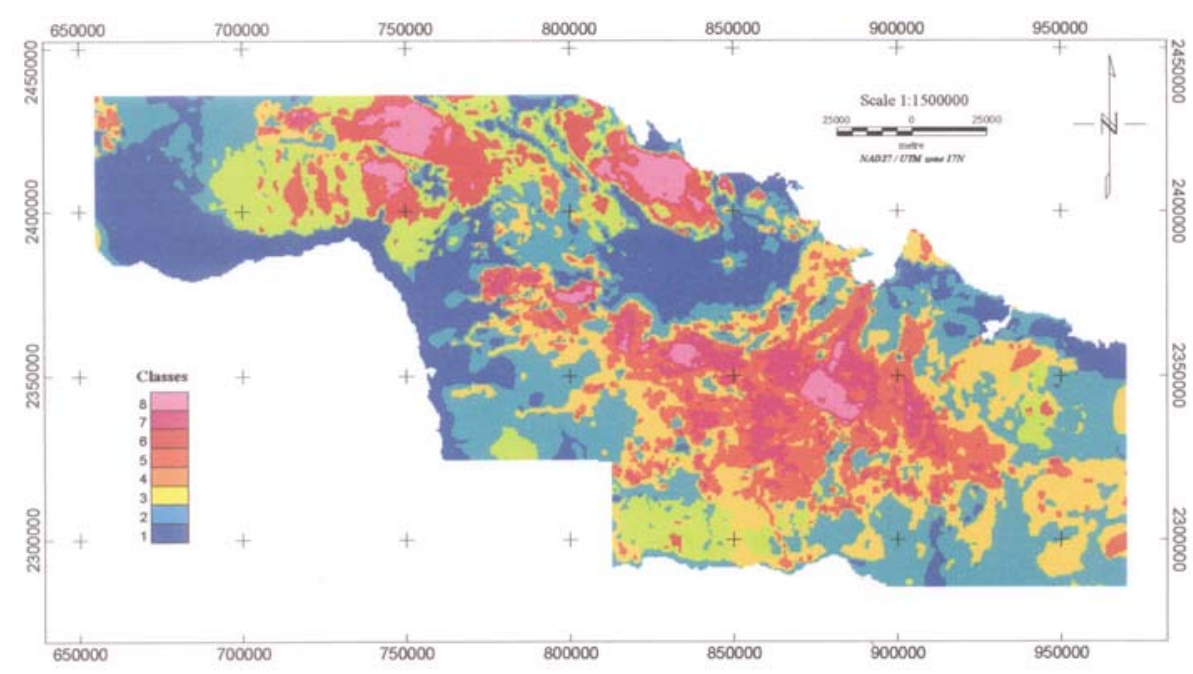

Figura 8 - Mapa de classificação não-supervisionada da espectrometria de raios gama aérea, Cuba centro-oriental. Figure 8- Unsupervised classification map of the airborne gamma-ray spectrometry, central-eastern Cuba.

Tabela 2 - Estatística da análise de grupamento (cluster analysis) das variáveis CT, K, eTh e eU. Table 2- Cluster analysis statistics of the $C T, K$, eTh and el data.

\begin{tabular}{|c|c|c|c|c|c|c|c|c|c|c|c|c|}
\hline & \multicolumn{3}{|c|}{ contagem total $(\mu R / h)$} & \multicolumn{3}{|c|}{ potássio (\%) } & \multicolumn{3}{|c|}{ tório (ppm) } & \multicolumn{3}{|c|}{ urânio (ppm) } \\
\hline & $\begin{array}{c}\text { Valor } \\
\text { mínimo }\end{array}$ & $\begin{array}{c}\text { Valor } \\
\text { máximo }\end{array}$ & Média & $\begin{array}{c}\text { Valor } \\
\text { mínimo }\end{array}$ & $\begin{array}{c}\text { Valor } \\
\text { máximo }\end{array}$ & Média & $\begin{array}{c}\text { Valor } \\
\text { mínimo }\end{array}$ & $\begin{array}{c}\text { Valor } \\
\text { máximo }\end{array}$ & Média & $\begin{array}{c}\text { Valor } \\
\text { mínimo }\end{array}$ & $\begin{array}{c}\text { Valor } \\
\text { máximo }\end{array}$ & Média \\
\hline Classe 1 & 0.8 & 2.7 & 2.0 & 0.1 & 1.5 & 0.7 & 0.3 & 5.5 & 1.2 & 0.3 & 2.2 & 0.9 \\
\hline Classe 2 & 2.3 & 3.5 & 2.8 & 0.3 & 1.5 & 0.9 & 0.1 & 4.4 & 1.5 & 0.3 & 3.3 & 1.4 \\
\hline Classe 3 & 2.5 & 5.1 & 3.9 & 0.1 & 1.7 & 0.7 & 3.1 & 10.2 & 5.2 & 0.2 & 4.4 & 1.9 \\
\hline Classe 4 & 3.0 & 4.5 & 3.6 & 0.4 & 2.2 & 1.3 & 0.1 & 3.9 & 1.5 & 0.5 & 4.9 & 1.5 \\
\hline Classe 5 & 3.9 & 5.9 & 4.6 & 0.4 & 2.8 & 1.9 & 0.1 & 5.5 & 1.7 & 0.3 & 5.4 & 1.9 \\
\hline Classe 6 & 4.5 & 9.1 & 5.9 & 0.3 & 2.1 & 0.8 & 5.2 & 18.5 & 9.4 & 0.4 & 6.7 & 3.4 \\
\hline Classe 7 & 5.1 & 8.8 & 5.1 & 0.6 & 5.2 & 2.5 & 0.2 & 7.4 & 1.9 & 0.5 & 8.8 & 2.3 \\
\hline Classe 8 & 7.0 & 15.3 & 9.1 & 0.5 & 6.9 & 1.8 & 0.5 & 18.3 & 8.3 & 0.5 & 15.8 & 6.2 \\
\hline
\end{tabular}


A classe 3, localizada principalmente a noroeste e sul da área (Figura 8), apresenta elevados teores de tório, baixos de potássio e relativamente baixos de urânio (Tabela 2), associados ao desenvolvimento de crostas lateríticas em sedimentos recentes.

As classes 4 e 5 apresentam uma ampla distribuição nas porções centrais e centro-leste do setor (Figura 8). Os teores dos radioelementos apresentam uma distribuição bastante homogênea, observando-se um leve incremento dos teores de potássio (Tabela 2), o que é justificado pela associação destas classes com as formaçoes vulcânicas de composição variada pertencentes ao Arco Vulcânico Cretácico.

A classe 6 abrange setores à noroeste e norte da área (Figura 8), exibindo um predomínio de teores anômalos de tório (Tabela 2). Esta classe é localmente relacionada à classe 3 e sua resposta é também devida a presença de crostas lateríiticas sobre sedimentos.

A classe 7 é mais restrita à porção central do setor, com certo predomínio na direção NW-SE, e apresenta elevadas concentrações de potássio e urânio (Figura $8 \mathrm{e}$ Tabela 2). Pelas características anteriormente descritas, esta classe é relacionada principalmente à cadeia de corpos plutônicos de composição cálcio-alcalina, pertencentes ao Arco Cretácico.

Localizada a noroeste, norte e ao longo da porção central do setor (Figura 8), a classe 8 (Tabela 2) compreende rochas de natureza geológica distinta. Na porção noroeste, essa classe mantém um vínculo com as classes 3 e 6 e, conseqüentemente, apresenta concentrações anômalas de tório relacionadas ao desenvolvimento de crostas lateríticas. Na porção norte do setor relaciona-se com áreas contendo teores anômalos de urânio, o que é provocado pelas concentrações de fosfatos presentes em rochas calcárias pertencentes à margem continental da Plataforma das Bahamas. Na porção central, a classe 8 exibe teores anômalos de potássio, os quais são relacionados à presença das seqüências alcalinas do arco.

\section{INTEGRAÇÃO E INTERPRETAÇÃO DOS DADOS GEOFÍ́IICOS}

Com intuito de fazer uma análise integrada dos ambientes geológico-tectônicos da área de estudo com os resultados obtidos nas duas classificaçōes anteriormente documentadas, foi confeccionado 0 mapa integrado (Figura 9) que será discutido de norte a sul.

Faixa A: localiza-se a longo da porção N-NE da área de estudo. A assinatura dos campos gravimétrico e magnético de valores positivos e baixo gradiente nessa faixa (classe 3 - Figura 7; Tabela 1), permite considerar a presença de rochas densas e magnéticas, típicas de embasamento continental. Esta interpretação é também suportada pelo fato de que ambientes geotectônicos continentais são caracterizados por campos gravimétricos e magnéticos elevados e de baixo gradiente, produtos da alta densidade e magnetismo das rochas que compõem 0 embasamento continental (MIRONOV, 1977; GRANT, 1985).

A gamaespectrometria nesta faixa é caracterizada fundamentalmente pela presença de concentraçōes elevadas e anômalas de urânio (classe 8 - Figura8, Tabela2), provocada por um possível incremento das concentrações de fósforo nos sedimentos. Segundo Dickson e Scott (1997), 0 incremento nas concentrações de urânio em rochas sedimentares formadas em mares pouco fundos e tranqüilos (ambientes plataformais) pode ser ocasionado pelas elevadas concentraçōes de fósforo $\left(P_{2}, O_{5}\right)$ redepositado nessas rochas.

Os resultados anteriormente expostos reforçam a noção de que a faixa "A" representa a porção norte do cinturão dobrado, constituído por sedimentos de idade jurássica-cretácea, pertencentes à margem continental da Plataforma das Bahamas, tal como descrito nos modelos de lturralde-Vinent (1997) e lturralde-Vinent e outros (2000).

Faixa B: localiza-se a sul da faixa "A" e também apresenta direção NW-SE. A porção oeste desta faixa é marcada por um campo gravimétrico (anomalia de Bouguer) de valores positivos baixos até negativos e altos gradientes, sendo o campo magnético mais variável, de valores positivos baixos até negativos e intensos gradientes de direção NW-SE (classe 2 - Figura 7; Tabela 1). 0 campo gravimétrico e 0 magnético a leste desta faixa apresenta assinatura caracterizada por valores negativos e ausência de gradiente (classe 2 - Figura 7; Tabela 1). A gamaespectrometria na faixa $B$ não apresenta uma clara especialização, sendo caracterizada por valores de background dos radioelementos (classes 1 e 2 - Figura 8; Tabela 2).

Uma análise da assinatura dos campos físicos nesta faixa permite supor que a mesma compreende o efeito simultâneo de diferentes eventos geotectônicos, não estando somente ligada a evolução da bacia de retroarco do AVC (ITURRALDE-VINENT et al., 2000). A porção oeste da faixa, marcada pela queda na intensidade do campo gravimétrico, reflete a presença da possível zona de subdução de direção SW de um abortado e erodido arco boninítico (KERR et al., 1999). Por sua vez, a porção mais a leste, caracterizada por valores negativos e ausência de gradiente dos campos, evidencia a presença conjunta das bacias de retroarco de ambos arcos vulcânicos.

Faixa C: abrange uma extensa área, começando a noroeste, passando pelo centro até 0 sudeste da área de estudo. Os campos magnético-gravimétrico anômalo se mostram, em geral, com valores positivos e altos gradientes de direção NW-SE, e intensas anomalias positivas profundas na porção central e sul (classes 5 e 6 - Figura7; Tabela 1). Também nesta faixa a oeste, sul e sudeste encontram-se setores caracterizados por extensas anomalias magnéticas-gravimétricas de 
valores negativos e ausência de gradiente (classes 1 e 2, Figura 7; Tabela 1).

A gamaespectrometria nesta faixa apresenta maior complexidade. No centro-oeste é marcante a especialização em tório e ocasionalmente urânio, tornando-se majoritariamente potássica a leste, numa cadeia de valores anômalos de direção NW-SE, e a sul, com valores anômalos locais (classes 4, 5 e 7 - Figura 8; Tabela 2).
A análise das assinaturas geofísicas expressas na faixa " $\mathrm{C}^{\text {", }}$ com base nos atuais modelos geológicos (ITURRALDE-VINENT, 1997; KERR et al., 1999; ITURRALDE-VINENT et al., 2000), permite considerar esta faixa como representativa da parte ativa do arco cretácico (bacia axial), constituída por corpos plutônicos, subvulcânicos, lavas de variada composição (PÉREZ; SUKAR, 1997; PIÑEIRO; QUINTANA; MARÍ, 1997; MARÍ, 1997) e formada como consequiência da subdução do arco a sul do arquipélago (no atual Mar Caribe), mergulhando para NE.

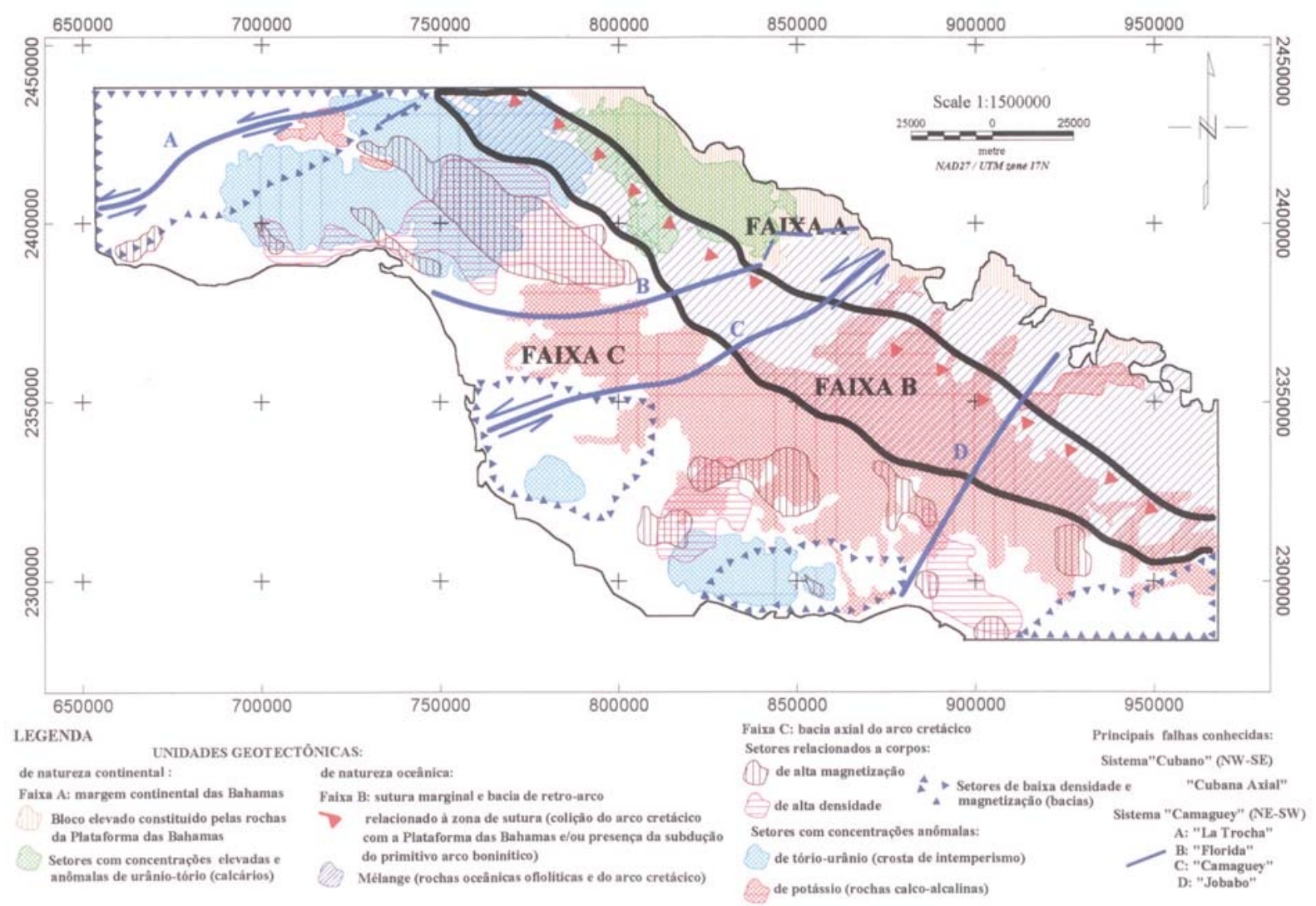

Figura 9 - Mapa integrado de dados geofísicos (aeromagnetometria, aerogamaespectrometria e gravimetria), Cuba centro-oriental. Figure 9- Integrated map of geophysical data (airborne magnetic and gamma-ray spectrometry data and gravimetric data), central-eastern Cuba. 


\section{CONCLUSÕES}

A classificação não-supervisionada relacionou os dados geofíisicos aos ambientes geológico-tectônicos e estágios magmáticos presentes em Cuba centro-oriental.

Os dados aeromagnéticos e gravimétricos foram agrupados em seis classes, relacionadas às estruturas de bacia decorrentes de blocos abatidos, sequëncias vulcänicas e focos magmáticos do AVC, e ainda, rochas continentais pertencentes à Plataforma das Bahamas.

Os dados aerogamaespectrométricos foram agrupados em oito classes relacionadas às crostas lateríticas, formações vulcânicas e corpos plutônicos do AVC, e rochas calcáreas continentais.

Este trabalho permitiu não só determinar as assinaturas geofíisicas, como associá-las à geologia, contribuindo para detalhar o mapa geológico de Cuba centro-oriental.

\section{Agradecimentos}

Os autores agradecem a FAPESP (processo 94/03700-0) pelo financiamento da pesquisa. eà Dirección Técnica del Instituto de Geologia y Paleontologia (IGP-Cuba), pela concessão da base de dados geofíisicos. C.R. Souza Filho agradece ao CNPq pela bolsa de Produtividade em Pesquisa (Proc. No. 301.227/94).

\section{REFERÊNCIAS}

BARANOV, V. A new method for interpretation of aeromagnetic maps: pseudogravitmetric anomalies. Geophysics, [S.I.], v. 22, p. 359-383, 1957.

CRÓSTA, A. Processamento digital de imagens de sensoriamento remoto.Campinas: Instituto de Geociências da Unicamp, 1993.

DAVIS, C. D. Statistics and data analysis in geology analysis of multivariate data. New York: John Wiley \& Sons, 1976.

DICKSON, B. L.; SCOTT, K. M. Interpretation of aerial gamma-ray survey adding the geochemical factor. AGSO Journal of Australian Geology \& Geophysics., [S.I.], v. 17, p. 187-200, 1997.

DUVAL, J. S; VULKAN, N. U. Multivariate statistical analysis of geophysical data in Nevada. Geophysics, [S.I.], v. 58, p. 749-755, 1993.

GRANT, F. S. Aeromagnetic, geology and ore environments. Geoexploration, [S.I.], v. 23, p. 303-362, 1985.

EBERLE, D. Geological mapping based upon multivariate statistical analysis of airborne geophysical data. ITC Journal, [S.I.], n. 2: p. 173178, 1993.
HARRIS, J. R. Clustering of gamma ray spectrometer data using a computer image analysis system. In: AGTERBERG F. P.; BONHAM-CARTER, G. F. (Ed.). Statistical application in the Earth Sciences. Geological Survey of Canada, 1989. p. 19-31.

ITURRALDE-VINENT, M. A. Introducción a la Geología de Cuba. In: FURRAZOLA BERMÚDEZ, G.; NÚÑEZ CAMBRA, K. Estudios sobre la Geología de Cuba. Ciudad de la Habana: Instituto de Geología y Paleontología, 1997. p. 35-68.

et al. Geology of the Camaguey Region, Central Cuba Evolution of a Collisional margin in the Northern Caribbean. In: MILLER H.; HERVÉ F. (Ed.). Zeitschriff für Angewandte Geologie. Geoscientific Cooperation

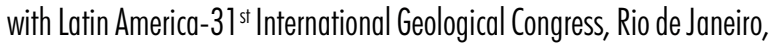
2000. p. 267-273.

KERR, A. C. et al. A new plate tectonic model of the Caribbean: Implications from a geochemical reconnaissance of Cuban Mesozoic volcanic rocks. Geological Society of American Bulletin, [S.I.], v. 111, n. 1, p. 581-1599, 1999.

MARÍ, T. M. Particularidades de los granitoides de Ciego de AvilaCamaguey-Las Tunas y consideraciones sobre su posición dentro del Arco de Islas. In: FURRAZOLA BERMÚDEZ, G.; NÚÑEZ CAMBRA, K. Estudios sobre la Geología e Cuba. Ciudad de la Habana: Instituto de Geología y Paleontología, 1997. p. 399-416.

MIRÓNOV, V. S. Curso de prospección gravimétrica. Barcelona: Reverte, 1977.

PARKS, J. M. Cluster analysis applied to multivariate geological problems. Journal of Geology, [S.I.], v. 74, p. 703-715, 1966.

PÉREZ, R. M.; SUKAR, S. K. Granitoides del Arco Volcánico Cretácico de la Región Central de Cuba (antigua provincia de Camaguey). In: FURRAZOLA BERMÚDEZ, G.; NÚÑEZ CAMBRA, K. Estudios sobre la Geología e Cuba. Ciudad de la Habana: Instituto de Geología y Paleontología, 1997. p.387-398.

PINEERO, P. E.; QUINTANA, M. E.; MARÍ, M. T. Caracterización geológica de los depósitos vulcanógeno-sedimentarios de la región de CiegoCamaguey-Las Tunas. In: FURRAZOLA BERMÚdEZ, G.; NÚÑEZ CAMBRA, K. Estudios sobre la Geología e Cuba. Ciudad de la Habana: Instituto de Geología y Paleontología, 1997. p. 345-356.

PIRES, A. C. B. Statistical characterization of greenstone sequences using magnetic and gamma-ray spectrometric data, Guarinos-Pilar de Goiás, Brazil. Revista Brasileira de Geociências, [S.I.], v. 20, p. 293-298, 1990. PIRES, A. C. B.; HARTHILL, N. Statistical analysis of airborne gammaray mapping purposes: Crixás-Itapaci area, Brazil. Geophysics, [S.I.], v. 54, p. 10-15, 1989. 
PIRKLE, F. L. et al. An example of cluster analysis applied to a large geological data set: aerial radiometric data from Cooper Mountain, Wyoming. Mathematical Geology, [S.I.], v. 16, p. 479-498, 1984.
PUSCHAROVSKY, Yuriy. Mapa Geológico dela República de Cuba. [S.I.] : Academias de Ciencias de Cuba y la Unión Soviética, 1988. 40 p. Escala 1:250.000.

\section{NOTAS SOBRE OS AUTORES}

Rigoberto Lazaro Prieto Cainzos formou-se em Engenharia Geofísica no Instituto Superior Politécnico "Jose A. Echeverria" ISPJAE (Cuba), em 1982. Até 1995 trabalhou no Instituto de Geologia e Paleontologia, como Especialista em Geofíisica, em diversos projetos relacionados à prospecção mineral, águas e geotécnica, sendo autor de vários relatórios téenicos. Foi responsável pelo Grupo de Vôo que realizou 0 Aerolevantamento nas regiões montanhosas de Cuba, em parceria com especialistas da antiga União Soviética. Em 2001 doutorou-se em Ciências, área de concentração Metalogênese no Instituto de Geociências da Universidade Estadual de Campinas (UNICAMP). Doutor do Laboratório de Ecologia da Paisagem (LEP), na Universidade Estadual de Londrina (UEL), desenvolve projetos de pesquisa junto ao Instituto Ambiental de Paraná (IAP-Londrina), na área de Geoprocessamento.

Elisabete Maria Pascholati é formada em Física pela UNESP, Mestre e Doutora em Ciências, modalidade Geofísica, pelo Instituto Astronômico e Geofísico da USP. É aposentada desde 1999 pela UNICAMP e trabalha, desde então, como Professora Voluntária Convidada junto ao Departamento de Geologia e Recursos Naturais do Instituto de Geociências, UNICAMP. Ministra aulas de Geofísica nos cursos de Graduaçãa e Pós-Graduação. Orienta Iniciação Científica, Mestrado e Doutorado. Faz parte do Grupo de Geotecnologias e tem trabalhado, principalmente, com dados magnéticos e espectrométricos de raios gama, aéreos e terrestres, visando mapeamento geológico, depósitos minerais e radiação ambiental natural.

Carlos Roberto de Souza Filho é engenheiro Geólogo graduado em 1988 pela Escola de Minas da Universidade Federal de Ouro Preto. Defendeu o Mestrado em Geociências na UNICAMP em 1991, o doutorado em 'Earth Sciences' na Open University, Inglaterra, em 1995, e a Livre Docência na UNICAMP em 2002. Atualmente é professor do Instituto de Geociências da UNICAMP, Chefe do Departamento de Geologia e Recursos Naturais, pesquisador do CNPp (nível 1) e líder do Grupo de Geotecnologias do IG. Suas contribuições em ciência estão concentradas na área de geotecnologias aplicadas ao estudo de recursos naturais, e compreendem diversos artigos publicados nas principais revistas nacionais e internacionais de geociências. 
